\title{
Preliminary Assessment of Fish Aggregating Devices (FADs) in the North and South Coast of Kenya
}

\author{
Fatuma Mzingirwa1, Muhammed Najya ${ }^{2 *}$, Mueni Elizabeth ${ }^{3}$, Charles Muthama ${ }^{1}$, \\ Peter Musembi ${ }^{4}$ \\ ${ }^{1}$ Kenya Marine and Fisheries Research Institute, Mombasa, Kenya \\ ${ }^{2}$ Pwani University, Kilifi, Kenya \\ ${ }^{3}$ State Department of Fisheries, Mombasa, Kenya \\ ${ }^{4}$ Marine Research and Conservation at A Rocha Kenya, Watamu, Kenya \\ Email:fmzingirwa@gmail.com, ‘n.muhammed@pu.ac.ke,emuenibf@yahoo.com, mussembip@gmail.com, \\ muthamacharles23@gmail.com
}

Received 1 March 2016; accepted 23 April 2016; published 26 April 2016

Copyright (C) 2016 by authors and Scientific Research Publishing Inc.

This work is licensed under the Creative Commons Attribution International License (CC BY).

http://creativecommons.org/licenses/by/4.0/

c) (i) Open Access

\section{Abstract}

Marine fisheries in Kenya mainly comprise of the artisanal fishermen who use non-motorized boats. Competition of these dwindling resources has led to overfishing and degradation of coral reef ecosystems. One of the methods which have been used to enhance sustainable exploitation of fisheries resources is the use of Fish Aggregating Devices (FADs). The study was conducted in two areas along the Kenyan coast which are: Msambweni in the southern part and Kuruwitu (Vipingo) in the northern part of the Kenyan coast. A combination of systematic site surveys: structured and semi structured interviews with key informants (community leaders and resource users); participant observations; descriptions of daily and seasonal time use; and analyses of secondary sources, such as fisheries records, was used to gather information and triangulate results. The perception of the community about FADs was determined by conducting a socio-economic survey before and after deploying FADs. Colonization and biomass survey around the deployed FADs was undertaken and fish associated with FADs was recorded. Results indicate that nine families of fish aggregated around FADs and at different distances. Catch and effort at FADs have been evaluated by monitoring catch data from fishers on daily basis after deployments.

\section{Keywords}

Fish Aggregating Devices (FADs), Artisanal Fishermen, Kenyan Coast, Msambweni, Kuruwitu (Vipingo)

\footnotetext{
${ }^{*}$ Corresponding author.
}

How to cite this paper: Mzingirwa, F., Najya, M., Elizabeth, M., Muthama, C. and Musembi, P. (2016) Preliminary Assessment of Fish Aggregating Devices (FADs) in the North and South Coast of Kenya. Open Journal of Marine Science, 6, $323-333$. http://dx.doi.org/10.4236/ojms.2016.62027 


\section{Introduction}

Kenya's coastline extends about $600 \mathrm{~km}$ along the seafront, from Somalia's border at Ishakani in the north (longitude $1^{\circ} 41^{\prime} \mathrm{S}$ ), to Tanzania's border at Vanga in the south (longitude $4^{\circ} 40^{\prime} \mathrm{S}$ ). A distinctive feature of Kenya's coastline is a fringing coral reef running parallel to the coastline from Vanga to Malindi bay [1]. Kenya's continental shelf is relatively narrow about 5 - $10 \mathrm{~km}$ wide with depth dropping to below $200 \mathrm{~m}$ in under $4 \mathrm{~km}$ of the shoreline. The coastal climate of Kenya is influenced mainly by large scale pressure systems of Western Indian Ocean and Monsoon winds. The monsoon blow from Northeast between December and March (Kaskazi) and from South east (Kusi), between May and October with 1 - 2 months transition periods characterised by variable and weaker winds.

Marine artisanal catches have oscillated between 7000 and 8000 metric tons annually for the last decade. Most of marine fishing in Kenya is small-scale artisanal that operates in the coastal near-shores [2]. Competition of these dwindling resources has led to overfishing and degradation of coral reef ecosystems.

Marine fisheries in Kenya are mainly artisanal (approximately 9017 artisanal fishermen utilizing 2233 fishing crafts) and undertaken mostly from small, non-motorized boats such as outriggers, dhows, cataracts and planked pirogues. Only about $10 \%$ of fishing crafts are motorized [3]. This constraint limits most of the fishing effort to inside the reef and rarely is fishing undertaken beyond territorial waters $(20 \mathrm{~km})$ except for a few commercial companies.

Local fishers use the most rudimentary equipment which has exacerbated the problem of over fishing in inshore coastal waters especially in the reef systems. The most common fishing methods used are gillnets, traditional traps, seine nets, long line, hook and line and others. The artisanal fleet is composed of different vessel types with two being the main target for tuna; these are the outrigger vessels and dhows.

Fish Aggregating Devices (FADs) are man-made structures set to float or anchored at a desired location in the sea to aggregate fish thus rendering their capture easier and may vary in shape and size, and can be either anchored or drifting [4]. This strong association between certain fishes and floating objects like FADs has been exploited by humans throughout history [5] and [6]. FADs appeared in the early 80's as "miracle solutions for making populations of tunas available to small scale fisheries" [7] [8]. A simple FAD typically can be made of bamboo rafts, strings of fishing floats or metal cylinders, all with appendages (branches, ropes, or disused netting) suspended beneath to provide shelter for small fish.

This study is aimed at assessing the effectiveness of FADs in increasing the amount of fish catch to the artisanal fishers and reducing pressure on the coral reefs. Analysis of the outcomes shall shape future policy regarding the use of fish aggregating devices as a means to increase fish catches so as to improve incomes and food security of the coastal Kenyans.

\section{Materials and Methods}

FADs were constructed using locally available materials like bamboo rafts and coconut fronds which are not only cost effective but also friendly to the environment, which were deployed near shore so that the local fishermen could get access and fish around them. Additionally they were deployed in areas far from the reef systems so as to conserve them. Fishing around FADs will enable fishermen to use less energy and time while they maximise on high fish catches. This enables people involved in small-scale fisheries to target and catch fish species that otherwise would be difficult, if not impossible for them to catch, such as tuna. The use of FADs will enable the diversification and improvement of livelihood opportunities through allowing access to potentially high-value fishery resources.

\subsection{Study Area and Site Survey}

The study was conducted in two areas along the Kenyan coast, Kuruwitu (Vipingo) northern part of the Kenyan coast and Msambweni in the southern part of the Kenyan coast. These sites were chosen since they were among the active fish landing sites along the coastline with a higher concentration of artisanal fishers and qualitatively represent a typical coral reef, lagoon-based fisheries of Kenya with a variety of fishing gears and vessels in use. At these sites, reconnaissance site surveys was undertaken to confirm the site requirements for FADs location.

Guidelines contained in the South Pacific Commission (SPC) Manual Vol. 1: Planning FAD Programmes [9] was followed in site selection. Perception of local fishermen to the devices was considered before deploying the FADs through discussions with the local fishers and site visits. Influence of wind and currents, tuna fisheries, 
customary fishing grounds, offshore shipping and industrial fishing activities, local oceanographic and navigational charts was also explored.

\subsection{Socio Economic Survey}

Socio economic impact of fishers at Msambweni and Kilifi was determined prior to setting the FADs. Data and information was collected using questionnaire on the understanding and the perceptions of the fishing communities towards these devices before deployment. Information on fisher demographics, diversity and fishing behaviour (gears, vessels used) among others was gathered from the study sites. A combination of systematic site surveys; structured and semi structured interviews with key informants (community leaders and resource users); participant observations; descriptions of daily and seasonal time use; and analyses of secondary sources, such as fisheries records, was used to gather information and triangulate results.

\subsection{FAD Development and Construction}

This study adopted a local fabricated FAD design using locally available materials. All materials for the construction of the FADs were sourced locally.

Local communities were tendered to supply bamboo rafts and palm fronds to be used to construct the FAD floaters and aggregators respectively. The rationale for using cheap materials such as bamboo and palm fronds to act as FAD floaters and aggregators is not only to achieve sustainability of the project but also for ecological reasons as these materials are biodegradable. However, both the FAD mooring lines and attachment ropes was fixed using polypropylene ropes to boost the longevity of the FADs. A local mason was tendered to construct the concrete blocks for anchoring the FADs using appropriate raw materials such as marine cement, ballast, iron rods, etc. The concrete blocks constructed were deployed by scuba divers using a boat. Five (5) fishers were invited to participate in the joint building activities of the FADs, which were aimed at building local capacity and ensure that these skills were transferred to the local fishers. Since local fishers were involved during gathering of FAD materials and construction of FADs, it was expected that the innovation will spin off directly to the fishers after completion of the project.

In the event of a possible project expansion, it is envisaged that the selected fishers who benefited from this initial training will train others in future.

\subsection{FADs' Deployment and Maintenance}

Since the local fishery is dominated by fishers without motorized boats, these FADs were deployed in locations of about 30 - $50 \mathrm{~m}$ depth that were easily accessible to the fishers. Deployment of two FADs one in each site was done at an interval of four week to ensure a smooth transition of the fishing behavior by the local fishers to this new technique. An out board engine boat was hired to deploy the FAD. Deployment of the FADs followed the simple "anchorlast" procedure [10]. After every two weeks a vessel was hired to note the status of the FADs in the sea. In case of any damage, the FADs parts were retrieved, repaired/replaced.

\subsection{Field Sampling of the FADs}

\subsubsection{Fish Catch Data}

Monitoring of catch and effort data from fishers was conducted on a daily basis. This data was compared to existing catch and effort data (baseline data) so as to determine the effect of FADs to the local fishery.

\subsubsection{FAD Colonization and Biodiversity Studies}

The dynamics of the aggregation in terms of species composition, interactions and information on the biomass at FADs was conducted. FAD colonization studies provided information on how long fish takes to fully colonize a FAD.

Biodiversity studies were to provide an inventory of species that are attracted to FADs, as an indicator of its viability and potential. The entire upper section of the FAD was inspected by divers for any aggregating fish. Both studies included continuous diving at FADs. Underwater Visual surveys (UVSs) were conducted at least $25 \mathrm{~m}$ of horizontal visibility. Dives were performed by three experienced divers equipped with SCUBA performing different roles. One of the divers recorded all the species encountered with their abundances and their 
estimated sizes on an underwater plastic sheet. The second one recorded videos of all the species and schools observed during the survey and the third, was in charge of the safety of the group. The visual censuses ranged between 45 and 60 min (duration), depending on the amount of fishes present and the environmental conditions according to the guidelines provided in [11] and [12].

\subsection{Data Analysis}

\subsubsection{Fish Catch and Effort Data}

All count data was examined by visually comparing plots of the proportion from each location. Data on the fishing gears and vessels presented as counts was classified using contingency tables. A number of hypothetical scenarios and explanatory variables were used to understand the socio-economic aspects of the fishers and predict the perceptions of fishers towards the FADs fishery.

Excel was used to carry out descriptive analysis and results presented using charts.

\subsubsection{Diversity and Abundance Estimates}

Direct abundance estimates of individuals by species was conducted when fish schools consisted of less than 50 individuals [12], while more abundant species was estimated by assigning them to abundance classes.

Videos were immediately viewed after each survey to verify the species lists and refine abundance estimates made underwater by surveying diver.

Minimum and maximum fish lengths of each species were estimated according to [13] to produce a biomass index.

\subsection{Reconnaissance Survey}

Following the guidelines contained in the South Pacific Commission (SPC) Manual Vol. 1: Planning FAD Programmes [9] Msambweni in the South and Kuruwitu in the North were found to be the best site for setting FADs according to the following reasons:

\subsubsection{South Coast (Msambweni)}

Physical factors: The sea floor consists of grass, corals and mud. Most of the sea floor here is gentle so the FADs have minimal chances of being dragged away. Fishermen go fishing at a depth of 20 - $50 \mathrm{~m}$ and are able to get the target species including pelagic species so FADs will be cost effective in terms of the mooring line that was used. There are occasional strong winds and currents especially during South East Monsoon winds but North East Monsoon winds are known to be calm and fishermen can go fishing with ease.

Operational factors: Tuna and other pelagics fish are abundant in Msambweni. Some of the species caught are Dolphin fish, Marlins, Tunas, Kingfish, carangids and these fish are known to be attracted by FADs. Fishermen in Msambweni have enough boats to access the FADs, they are using both canoe, sail boats and out board engine boats. Most of the fishermen here are using handline which are the right gears to fish around a FAD.

FADs and people: The fishermen at Msambweni are very enthusiastic about the FADs project and they are willing to cooperate in the maintenance for better usage of the FADs. The fishing grounds are shared by two major landing sites which are Mkunguni and Mwaembe and other minor landing sites of Munje, Gasi, Kinondo and Mwandamu. There were no restrictions on who access the fishing ground as long as no one uses destructive fishing methods. So far the fishermen at Msambweni have records of little conflicts among themselves and they promised to own the FADs and report any possible damages to enhance proper conditions. This was found out to be very important and contributed a lot in the decision for the site selection.

\subsubsection{North Coast (Kuruwitu)}

Physical factors: From the fishermen views, the area consists of both gentle and sloppy floors. Fishermen go fishing for about 5 - 10 miles from the shore line to catch pelagics and at a depth of $30-150 \mathrm{~m}$. This shows that the areas can easily be accessible by the fishermen. The area has fewer occurrences of strong winds and storms so this makes it easy for the fishermen to go fishing and also for the protection of FADs.

Operational factors: Kuruwitu is known to be abundant of pelagic fish though fishermen have less capacity to catch them due to the use of wrong fishing gears. Fishermen from the other nearby areas have had records on 
landings consisting of Tuna, King fish and Marlins which they fished from Kuruwitu. Here there are cold facilities to preserve fish and fish stalls where they can sell their catches.

FADs and people: Fishermen in Kuruwitu are also enthusiastic on FADs programme and it was promising that they are willing and able to use them when deployed. Some of them had a practical experience on FADs which happened by luck. There is a strong Beach Management Unit (BMU) which has good co-ordination and leadership so conflicts are minimal. Fishermen seemed to be ready to own the FADs and willing to report any possible damages. There are low risks of vandalism of FADs at Kuruwitu due to the strong BMU existing and the Locally Managed Marine Area (LMMA) which is very successful. This was the strongest point that led to the choice of the site. They strongly suggested to us that with proper sensitization the fishermen will take care of the FADs which will be put. There were no restrictions on who access their fishing ground so this ground is shared majorly among fishers from the neighboring BMUs.

\section{Results and Discussion}

\subsection{Site Survey at Sea}

Geographical coordinates were obtained using GPRS, which were used as reference points during deployment (Figure 1).

\subsection{Description of the Fishermen/Ownership of FADs}

From the interviews done in Kilifi and Msambweni, it was found out that $30.7 \%$ were at the age of 30 - 40 years, $22.7 \%$ at the age of 20 - 30 years, $18.2 \%$ at the age of 40 - 50 years and $28.4 \%$ were more than 50 years. Most of the fishermen interviewed did not have formal education (40.9\%), while fishermen with primary and secondary education were $45.5 \%$ and $13.6 \%$ respectively while no fisherman had any kind of tertiary education in both sites.

\subsection{Catch Composition}

Pelagic fish from North coast recorded the second highest catch compared to the rest of the group. It was notable that this was higher than demersal fish. While in South coast pelagic fish was third highest after mixed fish and demersals (Figure 2). Mixed fish comprises all the other types of fish at different unknown weight (kg) proportions. Majority of the fishermen along the Kenyan coast were found to obtain catches weighing $10 \mathrm{~kg}$ per day (Figure 3).

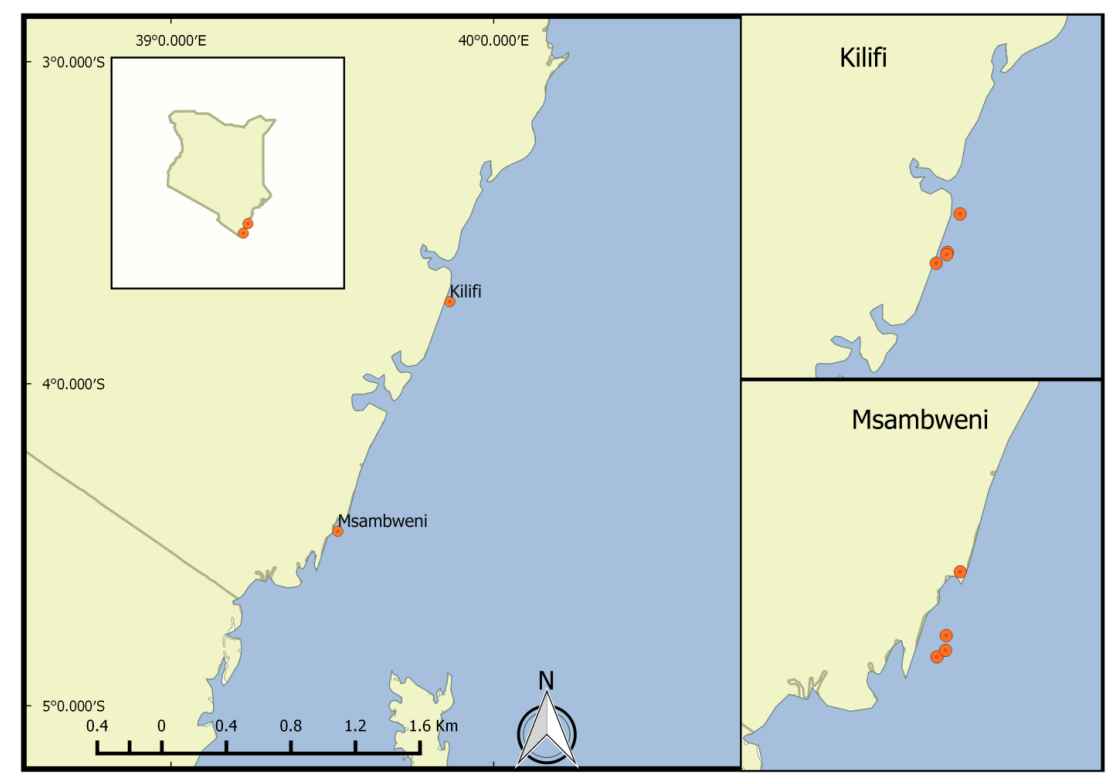

Figure 1. Study site. 


\subsubsection{Structure of Local Fleets: Boats and Gears}

There were three types of boats that were commonly used in both Kilifi and Msambweni which are canoe, outrigger boat and outboard engine boat but there was also another category of fishermen known as foot fishers who do not use boats when going for fishing. Outrigger boat is the most common type of a boat used and this was mainly in Msambweni, Outrigger boat uses both sail and paddle for propulsion, canoes was also common in Msambweni and less common in Kilifi, this only uses paddles for propulsion. A bigger proportion of foot fishers were observed in Kilifi (Figure 4).

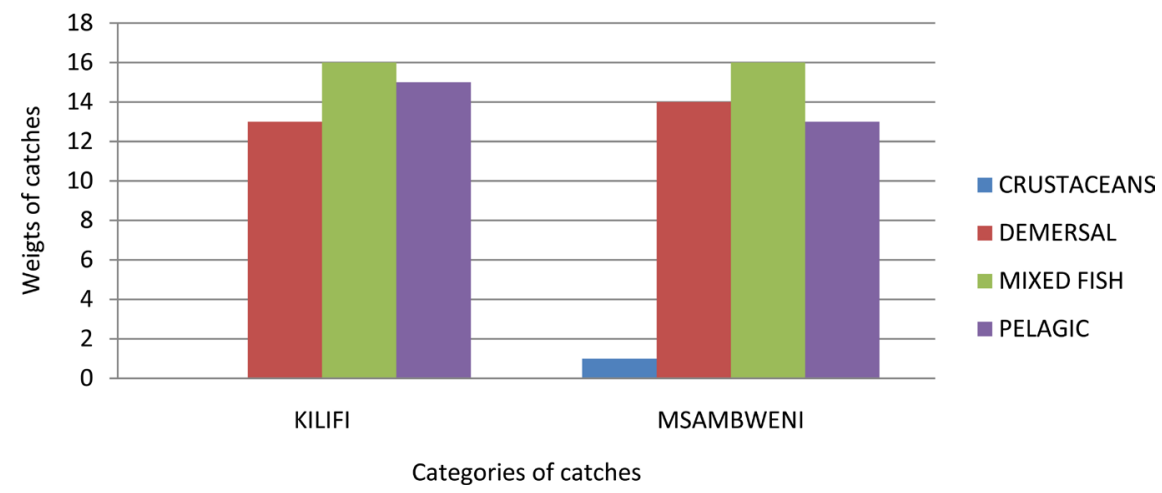

Figure 2. The categories of fish targeted by fishers of Msambweni and Kilifi.

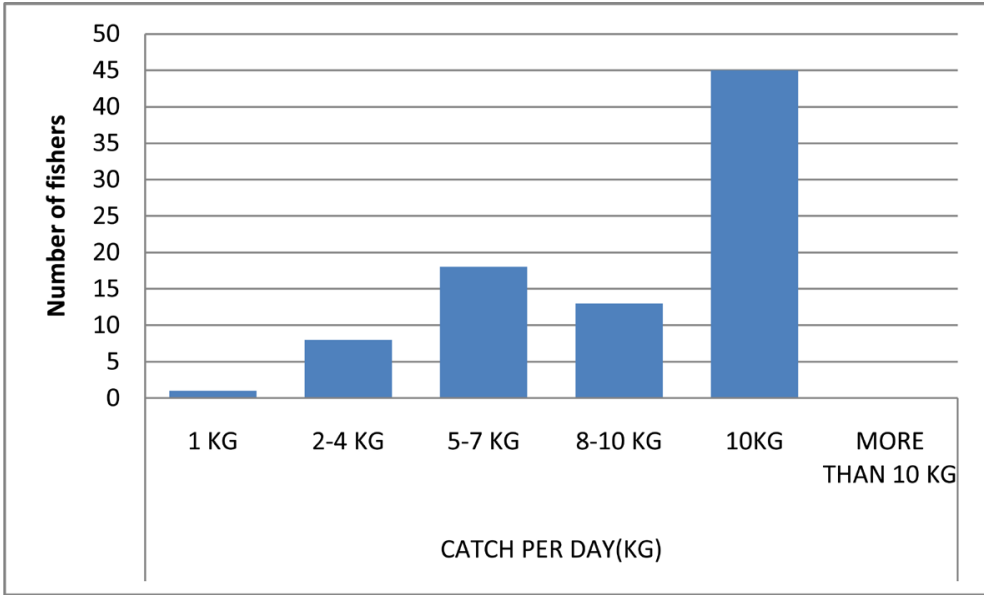

Figure 3. The overall fish catches of fishers per day.

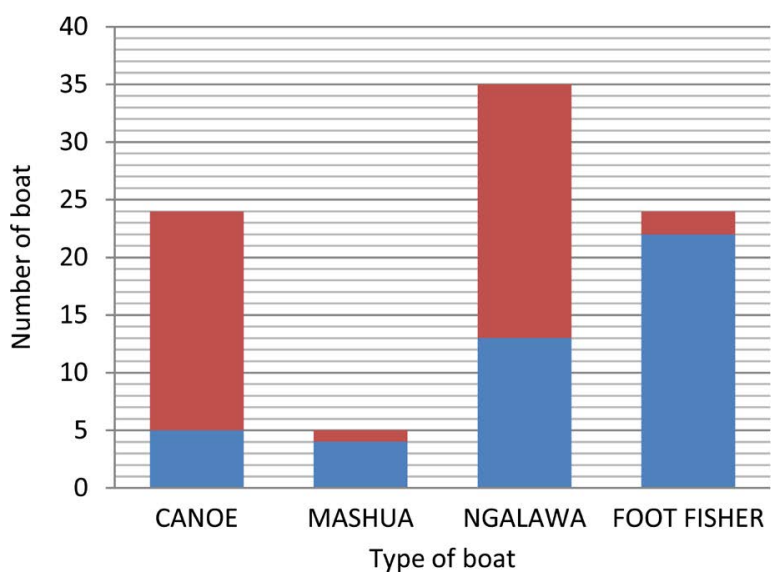

MSAMBWEN|

KILIFI

Figure 4. Types of boats used for fishing at Msambweni and Kilifi. 
The use of sailing was the most common mode of propulsion used at the study sites and also a bigger percentage used paddles (Figure 5). Very few fishermen used engines especially in Msambweni where none was observed, this is due to the poverty level of these regions.

In both sites hook and line was found to be the most preferred type of gear followed by gillnet, although fishermen in Kilifi still used spear gun for fishing which is illegal (Figure 6).

\subsubsection{Areas of Fishing}

Most of the fishing activities in Kilifi were concentrated at a distance less than $1 \mathrm{~km}$, this could have been attributed to the high proportion of foot fishers observed. In Kilifi there were fishermen with boats which were able to access up to $10-12 \mathrm{~km}$ and a few others more than $13 \mathrm{~km}$. In Msambweni fishers were distributed along the range of $1 \mathrm{~km}$ to more than $13 \mathrm{~km}$, majority could go fishing at a distance of $1-3 \mathrm{~km}$, followed by distance of $10-12 \mathrm{~km}$, and others at $4-6 \mathrm{~km}$. Fishermen who went fishing at more than $13 \mathrm{~km}$ were higher in Msambweni than in Kilifi (Figure 7).

\subsubsection{Preservation and Marketing of Products}

Fishermen in both Msambweni and Kilifi sell their catches to the fish traders who picked directly from the beach, this was at a percentage of $92.1 \%$ and only $4.6 \%$ took the catches to the market and $1.1 \%$ of all fishermen sold their catches to the fish companies, hotels and vessel owners. There was a very big percentage of fishermen operating in both Kilifi and Msambweni with no methods of preserving their fish, the proportion was $79.55 \%$ in Kilifi and $63.64 \%$ in Msambweni these fishermen instead sell their catches immediately to the fish traders (Figure 8).

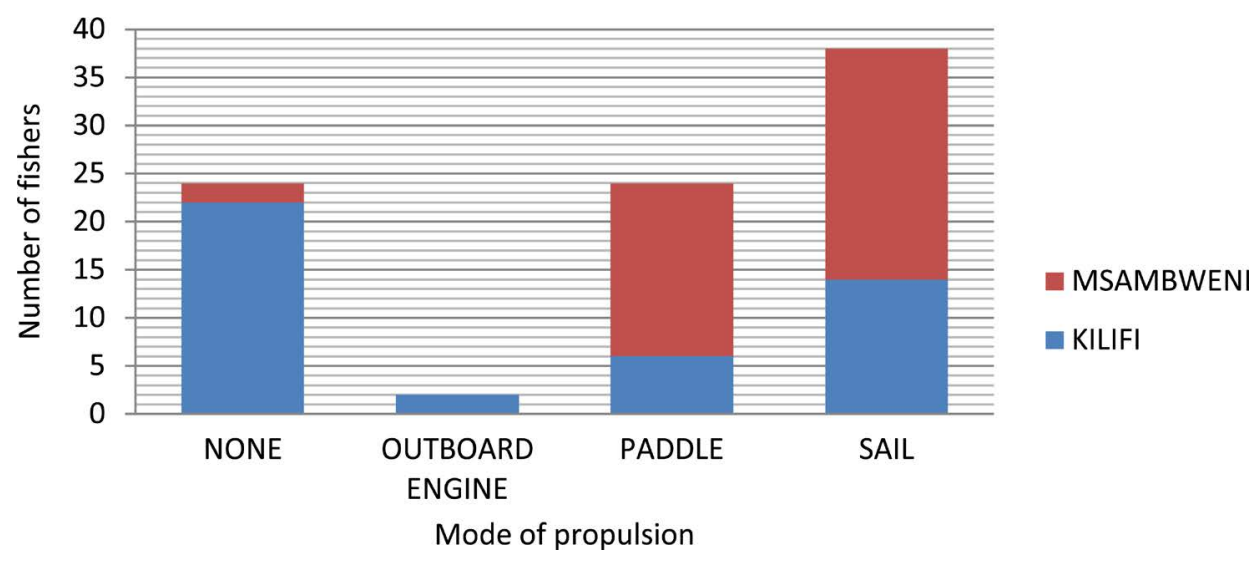

Figure 5. Mode of propulsion used during fishing at Msambweni and Kilifi.

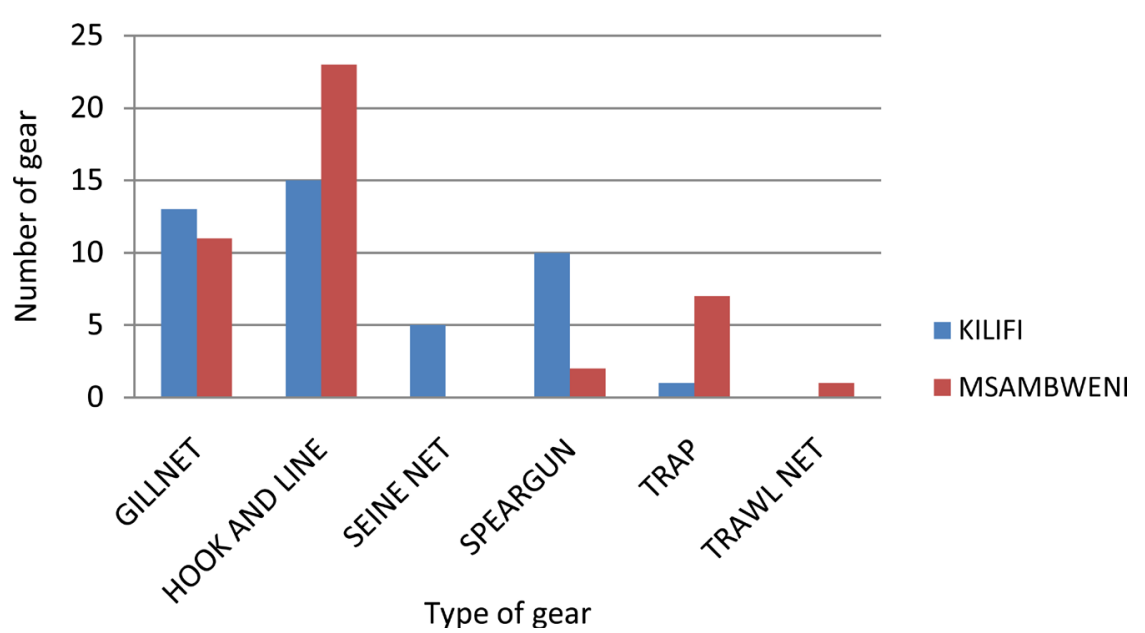

Figure 6. Type of gears used for fishing in Msambweni and Kilifi. 
Freezing as a method of preservation was however largely being used especially in Msambweni at 34.09\% and Kilifi at $13.64 \%$. Drying and smoking was also used for preserving fish in Kilifi at $4.55 \%$ and $2.27 \%$ respectively while in Msambweni smoking was not practiced at all while drying was only 2.27\% (Figure 9).

Potential factors for setting Fish aggregating devices in Kenya were based on the recommendations of [9]. Fish aggregating devices mainly attract pelagics and from the results outlined above, it was noted that, catch composition of the artisanal fishermen consisted mainly of the pelagic fish, this showed that there were presence of pelagics in the proposed sites, so FADs that were set would likely aggregate pelagic fish available in the area hence this would be of benefit to the fishermen. Among the fishing gears that were reported to catch pelagics were hook and line and gill nets which were among the most common gears used by the fishermen.

FADs were deployed at a distance of more than $3 \mathrm{~km}$ from the shore line and away from the reefs. From the results, more than $50 \%$ of fishermen in both sites could access fishing grounds of more than $3 \mathrm{~km}$; these were the grounds where FADs deployed because of ease of accessibility by the use of outrigger boat. Although, there were no well-established preservation methods, fishermen had a ready market to sell their catch. Probably the catches obtained were not large enough hence all could be sold immediately. However there were some form of preservation methods that existed in the two sites, this could be used to preserve catches of fishermen as FADs have been reported to increase fish catches of fishermen.

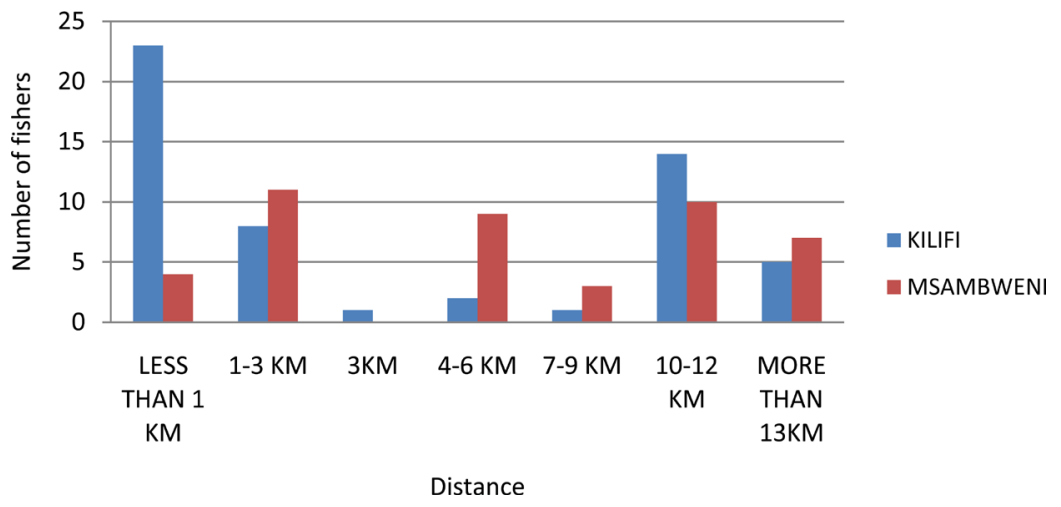

Figure 7. Distance fished at Kilifi and Msambweni.

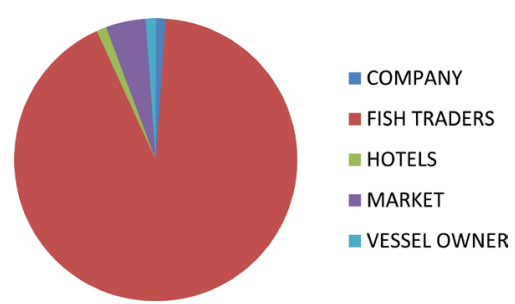

Figure 8. The percent of fish sold to company, fish traders, hotels, Markets and vessel owners.

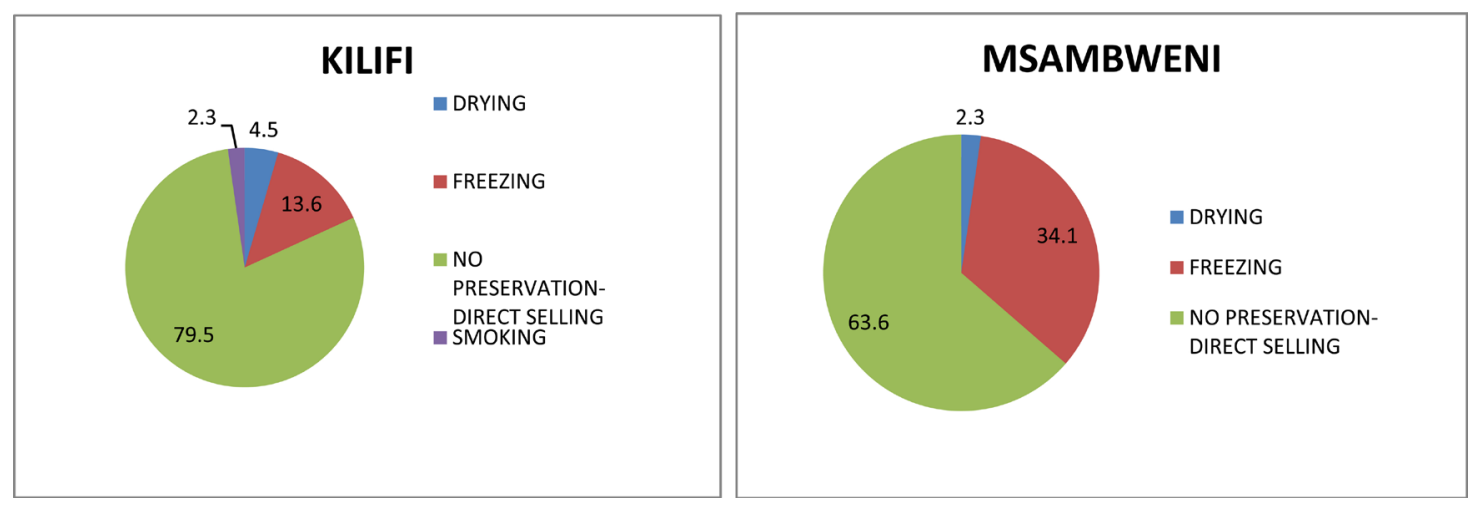

Figure 9. Percent of methods used for preservation of fish catches at Kilifi and Msambweni. 


\subsection{Deployment}

Three (3) FADs each have been deployed in Msambweni $\left(04.47017^{\circ} \mathrm{S}, 039.53802^{\circ} \mathrm{E} ; 04.546714^{\circ} \mathrm{S}, 039.50069^{\circ} \mathrm{E}\right.$; $\left.04.53724^{\circ} \mathrm{S}, 039.51439^{\circ} \mathrm{E}\right)$ and in Kilifi $\left(03.80469^{\circ} \mathrm{S}, 039.83307^{\circ} \mathrm{E} ; 03.69296^{\circ} \mathrm{S}, 039.88718^{\circ} \mathrm{E} ; 03.78001^{\circ} \mathrm{S}\right.$, $039.85871^{\circ} \mathrm{E}$ ), the activity involved participation of all the BMUs in the selected sites (Plate 1 ).

\subsection{Biomass and Diversity Study}

Visual survey around FADs was conducted and various species were obtained. Three level of fish were found to aggregate around FADs as follows: "intranatant species”, which remain within $0.5 \mathrm{~m}$ of the floating object, “extranatant species” (0.5 - $2 \mathrm{~m})$ and "circumnatant species” (+2 m), which are loosely associated with the object (Figure 10).

Eleven species belonging to seven families were identified within a week of the deployments of the FADs as follows; Carangidae, Scombridae, Pomacentridae, Haemulidae, Clupeidae, Sphyraenidae and Kyphosidae (Figure 11). Majority of fish identified were circumnatant meaning they were about two meters from the FADs.

\subsection{Catch and Effort}

There was inconsistency of catch and effort data collection due to vanderlisation of the device before their complete effectiveness. Figure 12 and Figure 13, summarise types of fish caught in Msambweni and Kilifi respectively, in the months of June and July 2014. In Msambweni, pelagic species were not amongst the common species caught while in Kilifi, Tunas, Baracudas and mackerels were among the pelagics caught with weights from as low as $10 \mathrm{~kg}$ to as high as around $550 \mathrm{kgs}$.

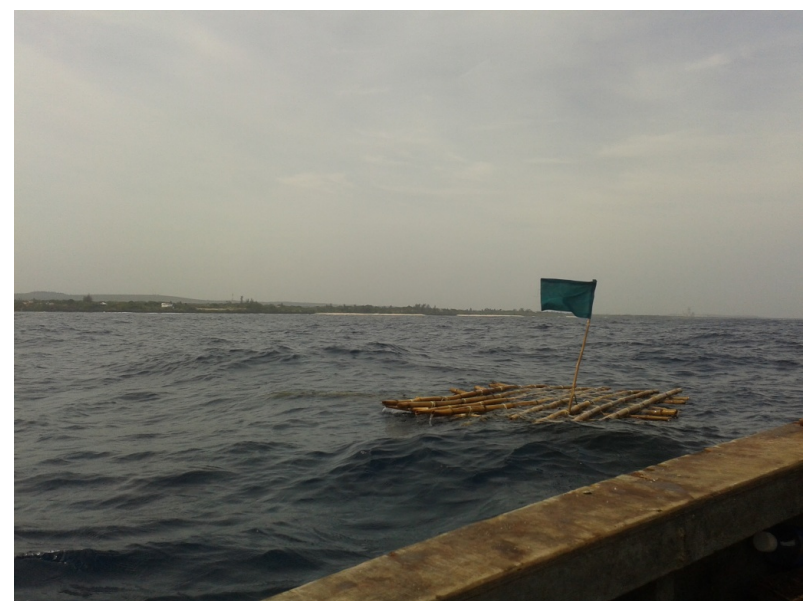

Plate 1. The fish aggregating device (FAD) deployed in Kuruwitu.

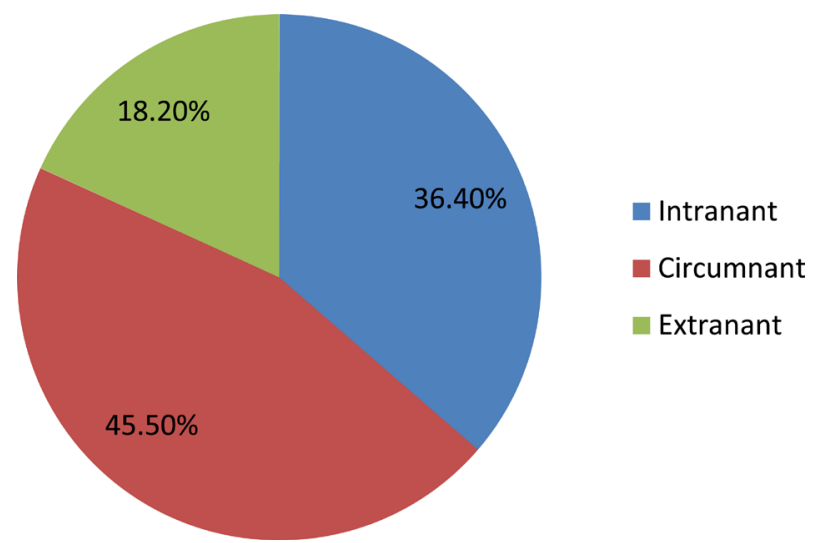

Figure 10. The proportion of level of fish aggregation around FADs. 


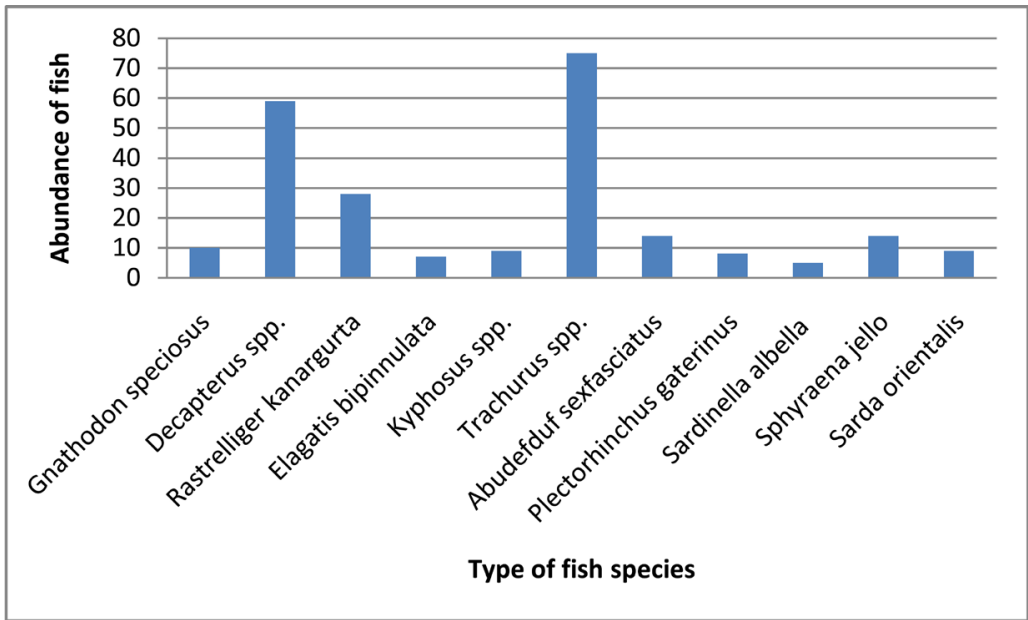

Figure 11. Total weights of common species caught in Msambweni (Mkunguni landing site) in the months of June and July 2014.

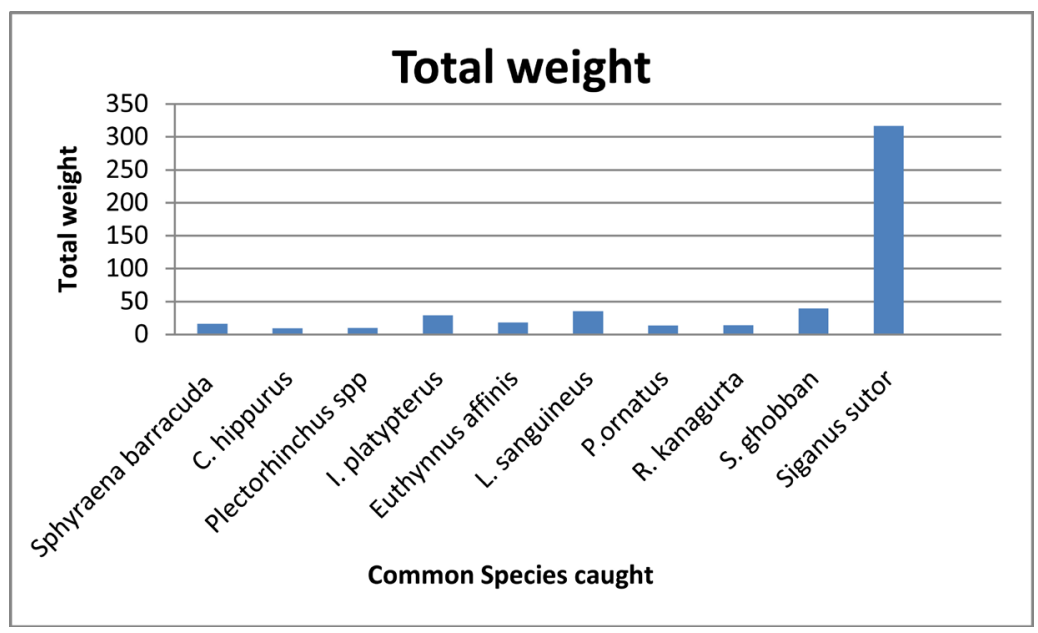

Figure 12. Total weights of fish caught in Kilifi (Takaungu landing site) in the months of June and July 2014.

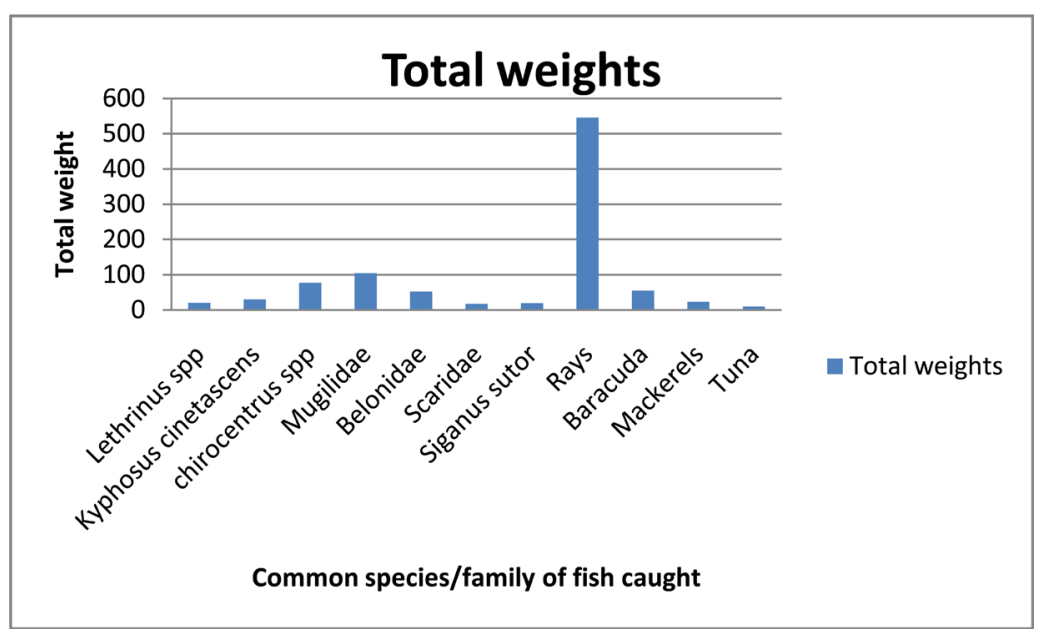

Figure 13. Total weights of fish caught in Kilifi (Takaungu landing site) in February. 


\section{Conclusion}

On the reconnaissance and socio economic survey, it was concluded that there is a good potential for the implementation of FADs in Kenya particularly because pelagic fish appeared to be sufficient to allow aggregation of fish around FADs. Fishermen are also able to access the FADs since inshore FADs were deployed at a distance of less than $5 \mathrm{~km}$. Visual survey around FADs was done twice after deployment and already eleven species had aggregated around them though at juvenile stage and eventually the large pelagics were expected to follow. A total of six (6) FADs were deployed, three (3) each in Kuruwitu and Msambweni catch. Data collected over the study period were not sufficient to describe the impacts of FADs on fishers catch. Long term monitoring of FADs is recommended to cover season variation in fish abundance.

\section{References}

[1] UNEP (2007) Kenya State of the Coast-Towards Integrated Management of Coastal and Marine Resources in Kenya.

[2] Samoilys, M.A., Maina, G.W. and Osuka, K. (2011) Artisanal Fishing Gears of the Kenyan Coast: CORDIO/USAID.

[3] Government of Kenya (2014) Marine Waters Fisheries Frame Survey Report. Ministry of Fisheries Development. State Department of Fisheries, Nairobi, 14.

[4] Franco, J., Dagorn, L., Sancristobal, I. and Moreno, G. (2009) Design of Ecological FADs.

[5] Jones, J. (1772) Oppian's Halieuticks of the Nature of Fishes and Fishing of the Ancients in V. Books. Translated from the Greek by J. Jones, with an Account of Oppian's Life \& Writings, and a Catalogue of His Fishes, Oxford.

[6] Morales-Nin, B., Cannizzaro, L., Massuti, E., Potoschi, A. and Andaloro, F. (2000) An Overview of the FADs Fishery in the Mediterranean Sea. In: Le Gall, J.-Y., Cayre, P. and Taquet, M., Eds., Peche thoniere et dispositifs de concentration de poisons, Ed. Ifremer, Actes Colloq, Vol. 28, 184-207.

[7] Sims, N. (1992) A Cost-Benefit Analysis of Fish Aggregation Devices (FADs) in the Artisanal Tuna Fishery in Rarotonga, Cook Islands. South Pacific Commission, Inshore Fisheries Research Project. Techn. Doc, Vol. 1, 10.

[8] Preston, G. (1982) The Fijian Experience in the Utilisation of Fish Aggregating Devices. South Pacific Commission, SPC Fisheries 14NP25: 61.

[9] Anderson, J. and Gates, P. (1996) South Pacific Commission (SPC) Fish Aggregating Device (FAD) Manual. Volume 1: Planning FAD Programmes. Secretariat of the Pacific Community, Noumea, New Caledonia.

[10] Fukofuka, S., Brogan, D. and Itano, D. (2004) The Development, Design and Current Status of Anchored and Drifting FADs in the WCPO. 17th Standing Committee on Tuna and Billfish. Majuro, Republic of the Marshall Islands, 11-18 August 2004, INF-FTWG-3.

[11] Graham, N.A.J., Wilson, S.K., Jennings, S., Polunin, N.V.C., Bijoux, J.P. and Robinson, J. (2006) Dynamic Fragility of Oceanic Coral Reef Ecosystems. Proceedings of the National Academy of Sciences of the United States of America, 103, 8425-8429. http://dx.doi.org/10.1073/pnas.0600693103

[12] Taquet, M. and Diringer, A. (2007) Guide des poissons de l’océan Indien et de la mer Rouge. Editions Quae, Versailles.

[13] Harmelin-Vivien, M. (1985) Tikehau atoll, Tuamotu Archipelago. Proceedings of the 5th International Coral Reef Congress, Tahiti, Vol. 21, 1-266. 